\title{
The Effect of Selected Technological Parameters of Laser Cutting on the Cut Surface Roughness
}

\author{
Jozef MEŠKO, Andrej ZRAK, Rastislav NIGROVIČ, Ružica R. NIKOLIĆ
}

\begin{abstract}
The theoretical part of the paper presents some basics of the laser cutting technology and principles. The characteristics of the $\mathrm{CO}_{2}$ laser beam and the parameters entering the laser cutting process are described. The conventionally used material - S235JR steel, method of its laser cutting and the effect of process technological parameters on the cut area characteristics are presented as well. Experimental investigations were performed on samples made of the S235JR steel, with application of different laser cutting technological parameters, while observing the surface roughness $R z$ and $R a$. Roughness results are displayed as images of the scanned cutting surface geometry and graphically for each sample, with comparison between the individual test samples. Effects of the position of the laser beam focus point, the cutting speed and assist gas pressure on the cut surface roughness are analyzed. It was concluded that the laser cutting parameters impose significant influence on the cut surface quality.
\end{abstract}

Keywords: assist gas pressure; cut surface quality; cutting speed; laser beam focus point position; laser cutting

\section{INTRODUCTION}

Laser cutting of metallic materials is done by the focused laser beam impact on the cut material. In technical and industrial practice, this cutting is performed by a circular laser beam, with diameter between $0.1 \mathrm{~mm}$ and 0.4 $\mathrm{mm}$. The size of the beam's diameter depends primarily on the nature and thickness of the cut material, as well as on the type of the laser cutting apparatus, and the $\mathrm{CO}_{2}$ laser power density reaches values up to $10 \mathrm{~kW}^{3} / \mathrm{cm}^{2}$, [1-4].

When the laser beam impacts the material it causes the material's rapid heating, virtually within milliseconds, all the way up to its melting temperature or even the evaporating temperature. The interactions between the cut material and the laser beam, as well as the processes that follow during the cutting, depend on the cut material chemical composition and on the initial quality of its surface, [5-8].

The process of the laser beam cutting is always preceded by drilling. It is necessary that a small hole is first drilled in the material that is going to be cut. The laser drilling process principle is somewhat different than that of the cutting. The laser beam, when impacts the drilled material, transfers the kinetic energy of photons, converting it to heat, what then causes the drilled material to melt and even partially evaporate. The immediate vicinity of the laser beam contact point at the drilled material contains ionized gasses, which then change to plasma. The cut material sublimates directly from the solid to the gaseous state, while the portion of it remains in the liquid state. Both the liquid and the gaseous materials are being blown away into the environment by the assist gas. This is how a small pit is formed into the drilled material and from it the laser beam can continue to penetrate deeper into the material, thus cutting it $[1-4,9,10]$.

When the oxidation process is concerned, in the laser cutting, the material at the contact point is heated up to the ignition temperature (flash point). It is then burnt in activated oxygen. The effect of oxidation on the laser beam consists of reducing its light reflecting coefficient and, by generating of additional heat, it causes the increase of the cutting speed. Thus, the cutting is actually an outcome of the exothermic reaction between the cut material and oxygen $[1,2,4,8-10]$.

The oxidation laser cutting is different from the fusion cutting, since it is using oxygen as an assist cutting gas. Reaction of oxygen with the metal, heated to the flashpoint temperature, generally leads to an exothermic reaction, which generates more heat and heats the material at the place of cutting. Based on the above effect, it is possible to obtain a higher speed of structural steel cutting than in fusion cutting. This property can, in turn, in continuous operation, lead to deterioration of the cutting process quality due to the cutting gap width, depth of the cutting surface roughening and heat affected zone. For that reason, the oxidation cutting is critical when cutting small shapes and acute angle geometries. By switching to the pulse mode, one can avoid burning up parts of the surface, because the pulse break between the individual pulses cools the material down, again to a lower temperature than that of the flashpoint, and the exothermic reaction ceases. The above-mentioned effect is used in cutting in conjunction with the laser power control in order to improve the cut quality, $[2,4,9,10]$.

Effect of the laser beam impact on the material being cut was studied by numerous authors. Because of the noncontact cutting effect, this process avoids the shearing deformation at the cutting edges. One important phenomenon in oxygen-assisted cutting is the formation of striation, which has received much attention since the early stage of laser cutting because it strongly affects the cut quality. It has become clear that the near-zero residual stresses and a minimum level of residual elements $(\mathrm{Cu}, \mathrm{Ni}$, $\mathrm{Cr}$ ) are necessary to obtain clean cuts and consistent cut quality, [11].

The cutting rate can be increased by directing the jet of gas that initiates the exothermic reaction right at the cutting point where the laser beam is focused. This also improves the accuracy of cutting, as well as refining the cut itself [12].

Temperature field during the laser forming of sheet metal was examined in [13]. The finite element method was applied for solving the governing equation of the heat transfer. It was shown that the temperature gradient in a depth below the surface increased with increasing of laser 
power and workpiece thickness, while it decreased by the laser beam scanning velocity.

Modelling of the laser cutting process and optimization of the process parameters has been addressed by many investigators to help understand the phenomena and basic mechanisms involved and to help predict the effects of process parameters. Owing to the complexity of the physical phenomena, those modelling efforts are normally focused only on particular aspects of the process under certain assumptions, $[14,15]$.

Some researchers were comparing the cut edge and the cut surface roughness obtained by laser cutting and by some other types of steels machining $[16,17]$. Effect of steel composition on the laser cut edge quality was considered in [18]. Influence of the laser cutting parameters on the HAZ was also considered in [19], where an attempt was made to obtain the best results with the lowest heat influence on the material being cut.

In the present article, the impact of selected technological parameters of laser cutting on the surface roughness parameters $R a$ and $R z$ was analyzed.

Surface roughness is defined as a deviation from the ideal form (shape) of a surface, presumably the smooth one. The deviations are measured in the direction of the vector perpendicular to that surface. If the deviations are large, the surface is considered as rough and vice versa if the deviations are small the surface is considered as smooth. The roughness of an object's surface can be used for defining how such an object would behave with respect to its environment. In engineering applications roughness is important in considering wear of various components, since the rough surface will wear faster, or it would cause faster wear of the surface with which it is in contact. Roughness of a surface can create sites for nucleation of cracks or as corrosion spots. Besides those negative effects, roughness can have the positive aspect, e.g. it can increase adhesion between the surface and some sort of deposited or glued (protective) coating.

By convention, every $2 \mathrm{D}$ roughness parameter is denoted by capital $R$ with a subscript that identifies the formula (parameter) that was used for quantifying the roughness. Different capital letters imply that the formula was applied to a different profile. The arithmetic average of the roughness profile is $R a$, while $R z$ is the average distance between the highest peak and the lowest valley in each sampling length [20].

\section{EXPERIMENTAL INVESTIGATIONS \\ 2.1 Experimental Material}

The tested steel, S235JR belongs to a group of S235 structural grade steels, with minimum yield strength of 275 $\mathrm{MPa}$, which is widely used in the engineering and construction industries. It is a low carbon, high tensile strength structural steel, which can be easily welded to other weldable steels. Due to the low carbon equivalent, it possesses good cold-forming properties. The structural applications of the S235 JR steel include freight cars, dump trucks, cranes and transmission towers, trailers, bulldozers and excavators, forestry machines, railway wagons, pipes, highway bridges, building structures, oil and gas platforms and offshore structures, fans, pumps, lifting equipment, etc. Laser cutting of these steel elements is a widely applied form of material processing [21].

For these experiments, the test samples were made by using the TruLaserL3030 laser-cutting machine (by TRUMPF). Measurement of the cut surface roughness was carried out on test samples made from the S235JR steel plate of thickness $s=2 \mathrm{~mm}$. The initial switching frequency during the cutting was set at $10.000 \mathrm{~Hz}$. A cutting head with the built-in lens with focal length of approximately $127 \mathrm{~mm}$ (5 inch declared by the manufacturer) was used. The three laser-cutting parameters were varied in these tests to establish their influence on the cut surface roughness: the position of the laser beam focus, the cutting speed and the assist gas pressure. The S235JR steel's chemical composition is shown in Tab. 1. [10,11].

Table 1 Chemical composition of steel S235JR Chemical composition of steel S235JR

\begin{tabular}{|c|c|c|c|c|}
\hline \multicolumn{6}{|c|}{ Chemical composition of steel S235JR } \\
\hline Elements & $\mathrm{C}$ & $\mathrm{Mn}$ & $\mathrm{S}$ & $\mathrm{P}$ \\
\hline Composition, \% & $<0.17$ & $<0.107$ & $<0.045$ & $<0.045$ \\
\hline
\end{tabular}

\subsection{The Position of the Laser Beam Focus Point}

The cutting process parameters values for this test were the following:

- Material: steel S235JR

- Assist gas: $\mathrm{O}_{2} 3.5$

- Focus point position: -3 to $3 \mathrm{~mm}$

- Cutting speed: 1 to $6.0 \mathrm{~m} / \mathrm{min}$

- Gas pressure: $0.45 \mathrm{MPa}$

- Power: $1200 \mathrm{~W}$

- Nozzle diameter: $0.8 \mathrm{~mm}$

- Nozzle distance: $0.7 \mathrm{~mm}$.

\subsection{The Cutting Speed}

The cutting process parameters values for this test were the following:

- Material: steel S235JR

- Assist gas: $\mathrm{O}_{2} 3.5$

- Focus point position: $-1 \mathrm{~mm}$

- Cutting speed: 1 to $6.0 \mathrm{~m} / \mathrm{min}$

- Gas pressure: $0.45 \mathrm{MPa}$

- Power: $1200 \mathrm{~W}$

- Nozzle diameter: $0.8 \mathrm{~mm}$

- Nozzle distance: $0.7 \mathrm{~mm}$.

\subsection{The Assist Gas Pressure}

The cutting process parameters values for this test were the following:

- Material: steel S235JR

- Focus point position: $-1 \mathrm{~mm}$

- Cutting speed: $5.0 \mathrm{~m} / \mathrm{min}$

- Gas pressure: 0.05 to $0.8 \mathrm{MPa}$

- Power: $1200 \mathrm{~W}$

- Nozzle diameter: $0.8 \mathrm{~mm}$

- Nozzle distance: $0.7 \mathrm{~mm}$. 


\section{RESULTS AND DISCUSSION}

\subsection{Effect of the Position of the Laser Beam Focus Point (ALP) on the Cut Surface Roughness}

The position of the focus point of the laser beam was varied within range -3 to $3 \mathrm{~mm}$. Measured values of the obtained surface roughness are presented in Tab. 2.

When cutting the experimental samples, the ALP setting value that determines the ALP position relative to the surface of the cut material, was progressively modified. The changes of values within the interval from $3 \mathrm{~mm}$ (which means that the laser beam focus point is $3 \mathrm{~mm}$ above the surface of the cut material), to $-3 \mathrm{~mm}$ (which means that the laser beam is focused so as to impact the material surface with the lower surface power density); the beam diameter gradually reduces along the material, and its focus point is situated at $1 \mathrm{~mm}$ below the bottom edge of the cut material.

Changes in the cut surface roughness values $R a$ and $R z$ can be seen on the investigated cut surfaces, Fig. 1. Roughness changes gradually from the parameters of the focus above the material surface to the values below the top surface of the cut material. The lowest cut surface roughness among the compared samples was measured on the experimental sample whose laser beam focus point was situated $3 \mathrm{~mm}$ above the surface of the material, Fig. 1. Looking at the cut off area, one can observe substantial corrugation of the material, which is caused by the impact of the laser beam. From this observation it follows that the material burning process is insufficiently stable, or even unstable, at the adjusted focal length ALP 3. The laser beam impacts the material and its maximum surface density of energy is achieved in a place situated outside the material being cut. The surface of the cut material is hit by a slightly diffused laser beam whose surface density decreases with gradual penetration deeper into the material. Material burning is relatively more stable when the focus point is set conversely, under the surface of the material. When the ALP focus point is set at $3 \mathrm{~mm}$ below the top surface of the cut material, the measured cut surface roughness is slightly greater, while when looking at the cut off area it is clearly seen that the burning process was more stable in this case. When the ALP focus point was set at 1 $\mathrm{mm}$ below the top surface of the cut material, the greatest roughness of the cutting area was measured, Fig. 2.

Table 2 Effect of the ALP position on the cut surface roughness

\begin{tabular}{|c|c|c|c|c|c|}
\hline Focus point position $(\mathrm{mm})$ & -3 & -1 & 0 & 1 & 3 \\
\hline Cut surface roughness $R a(\mu \mathrm{m})$ & 0.95 & 1.35 & 1.17 & 1.05 & 0.76 \\
\hline Cut surface roughness $R z(\mu \mathrm{m})$ & 3.38 & 4.03 & 3.47 & 3.31 & 2.54 \\
\hline
\end{tabular}

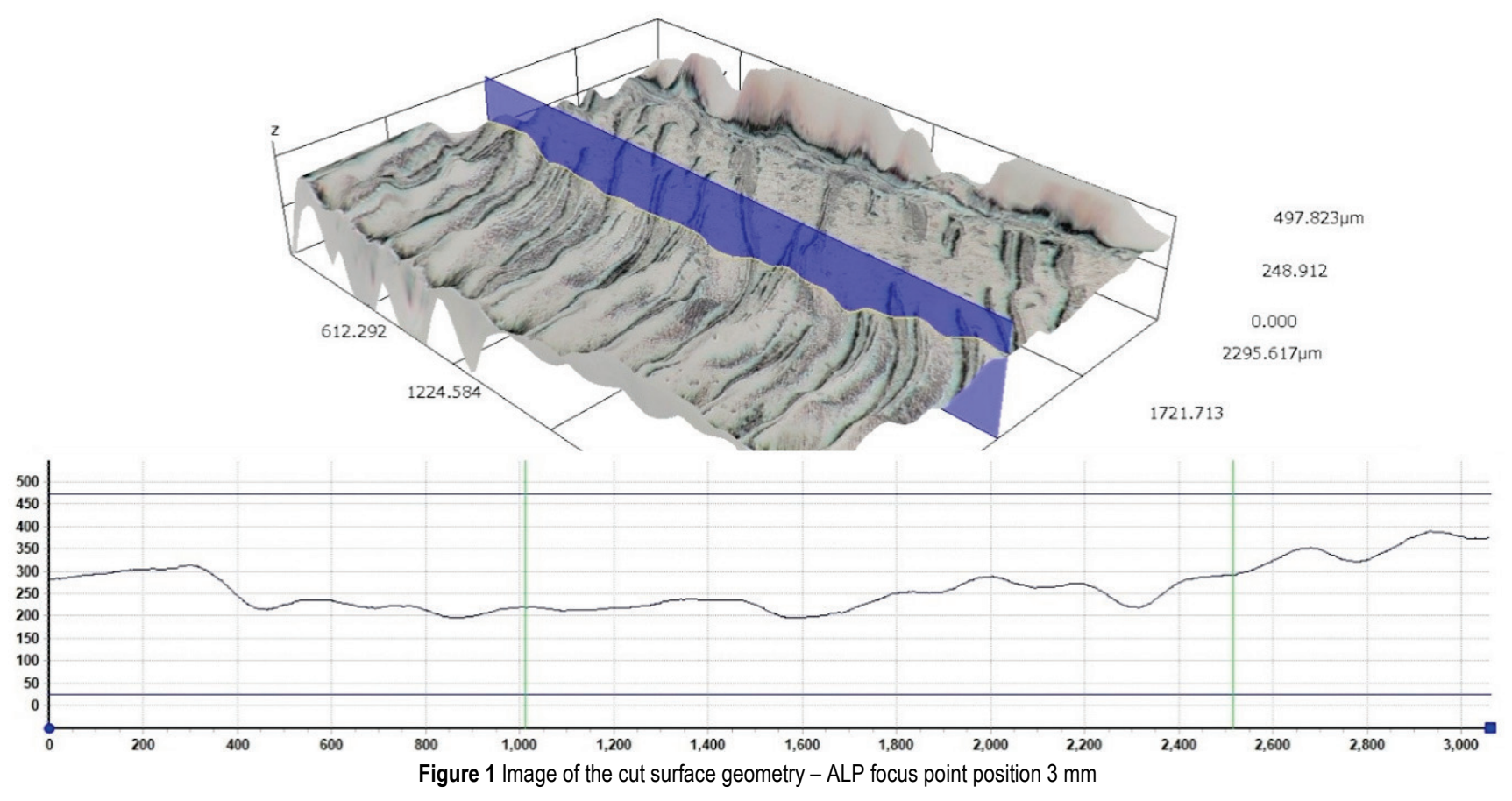

\subsection{Effect of the Cutting Speed on the Cut Surface Roughness}

The cutting speed of the laser beam was varied within range 1 to $6 \mathrm{~m} / \mathrm{min}$. Measured values of the obtained surface roughness are presented in Tab. 3 .

Table 3 Effect of the cutting speed on the cut surface roughness

\begin{tabular}{|c|c|c|c|}
\hline Cutting speed $(\mathrm{m} / \mathrm{min})$ & 1 & 2.5 & 6 \\
\hline Cut surface roughness $R a(\mu \mathrm{m})$ & 1.39 & 0.63 & 0.73 \\
\hline Cut surface roughness $\mathrm{Rz}(\mu \mathrm{m})$ & 4.68 & 2.35 & 2.27 \\
\hline
\end{tabular}

During the experimental samples cutting, the cutting speed was progressively modified $(1 \mathrm{~m} / \mathrm{min}, 2.5 \mathrm{~m} / \mathrm{min}$ and $6 \mathrm{~m} / \mathrm{min}$ ). Comparison of the measured values of the cut surface roughness (on samples with several changes in cutting speed) allows concluding that with increasing the cutting speed in the range of values between 2.5 and 6 $\mathrm{m} / \mathrm{min}$ the cut surface roughness slightly decreases. However, a cutting speed value set outside the above range causes significant increase in the cut surface roughness. In Figs. 3 and 4 is shown the surface roughness geometry for the cutting speed of $1 \mathrm{~m} / \mathrm{min}$ and $2.5 \mathrm{~m} / \mathrm{min}$, respectively. 


\subsection{Effect of the Assist Gas Pressure on the Cut Surface Roughness}

The assist gas pressure was varied within the range 0.05 to $0.8 \mathrm{MPa}$. Measured values of the obtained surface roughness are presented in Tab. 4.
Table 4 Effect of the assist gas pressure on the cut surface roughness

\begin{tabular}{|c|c|c|c|c|c|}
\hline Assist gas pressure $(\mathrm{MPa})$ & 0.05 & 0.15 & 0.30 & 0.60 & 0.80 \\
\hline Cut surface roughness $R a(\mu \mathrm{m})$ & 0.71 & 0.74 & 0.76 & 0.69 & 0.65 \\
\hline Cut surface roughness $\mathrm{Rz}(\mu \mathrm{m})$ & 2.29 & 2.26 & 2.39 & 2.49 & 2.12 \\
\hline
\end{tabular}
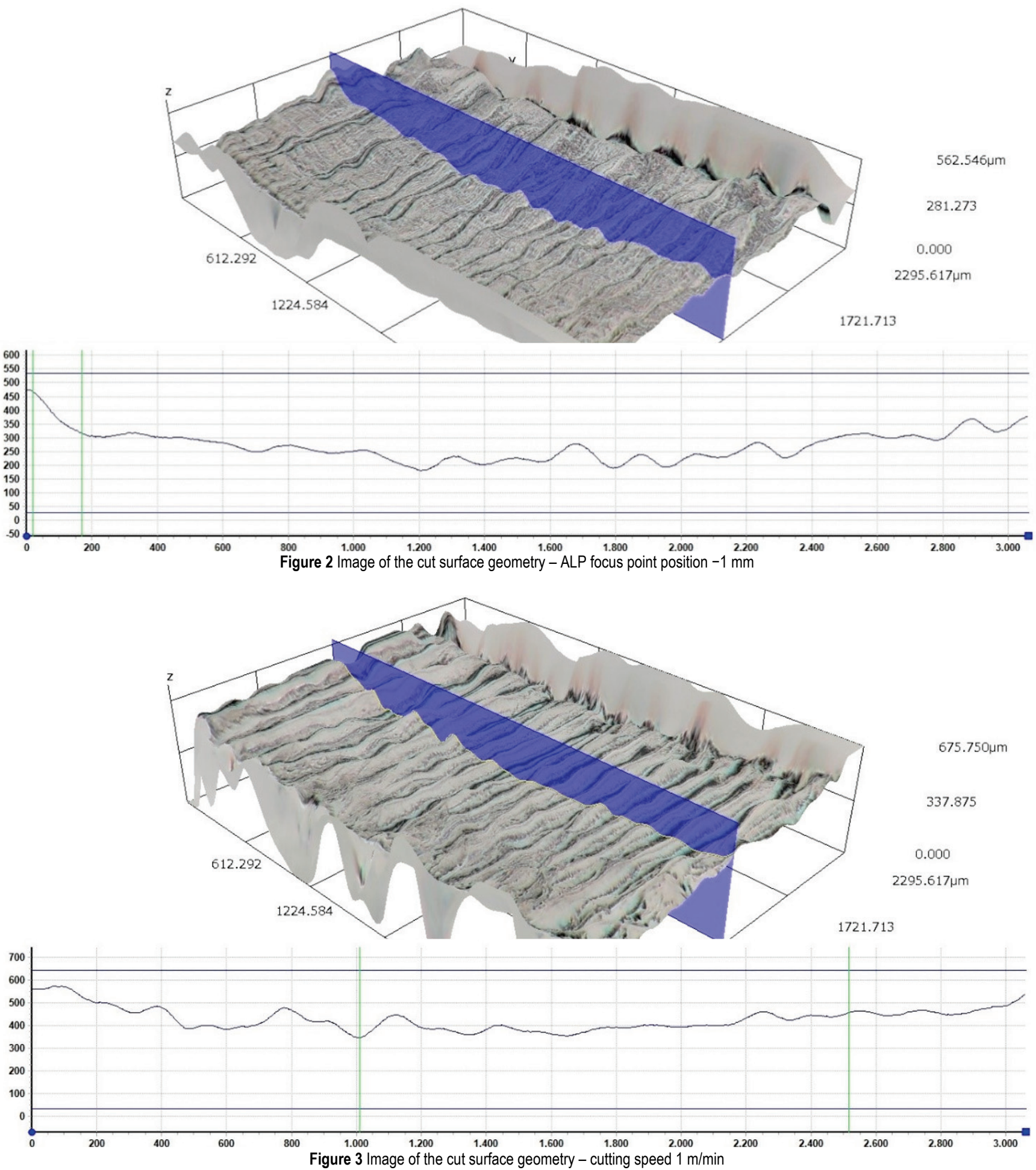

When considering the effect of changing the assist gas pressure, the values of the cut surface roughness parameters $R z$ and $R a$ were monitored. Both of those parameters were measured in a plane through the center of the experimental sample. Based on the analysis that was carried out, one could conclude that the maximum and minimum measured values of the cut material surface roughness did not differ significantly. Evaluation of the effect of the assist gas pressure change on the characteristics of the cut surface can also be done by analyzing the detailed images of the cut surface appearance, Figs. 5 and 6 . The cut surface is not planar 
when cutting was done with the application of the assist gas pressure lower than $0.15 \mathrm{MPa}$, including that value. The cut surface shape at the laser beam point of entry is significantly different from that at the laser beam point of exit from the cut material.
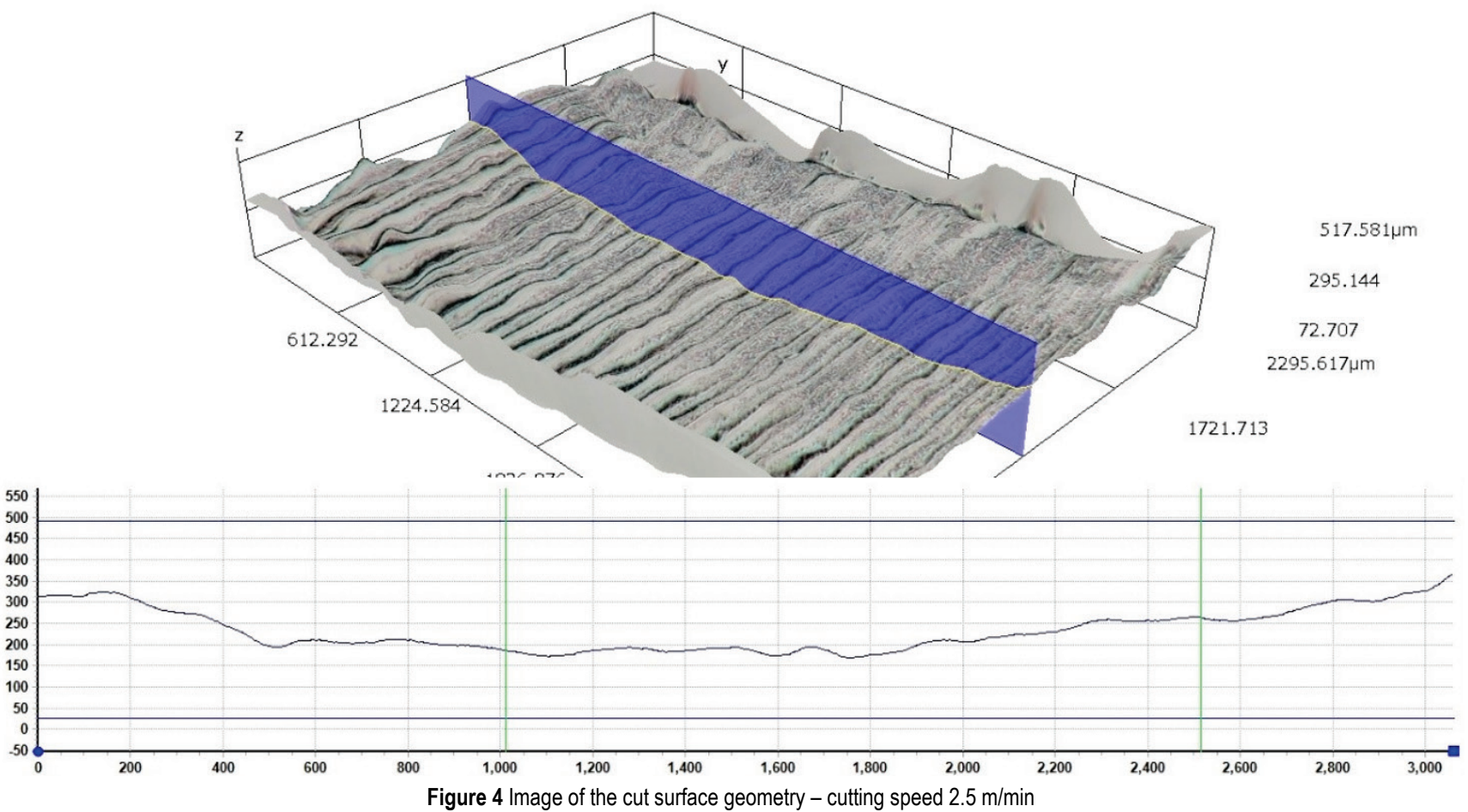

\section{CONCLUSIONS}

The paper presents an analysis and comparison of the effect of selected technological parameters of laser cutting of steel S235JR on the cut surface roughness. The material selection was guided by its wide applicability in different areas of structural engineering.

The variation of three important parameters of the laser cutting process was monitored in order to establish their influence on the quality of the cut surface. Each of them has different influence of the surface roughness parameters $R a$ and $R z$.
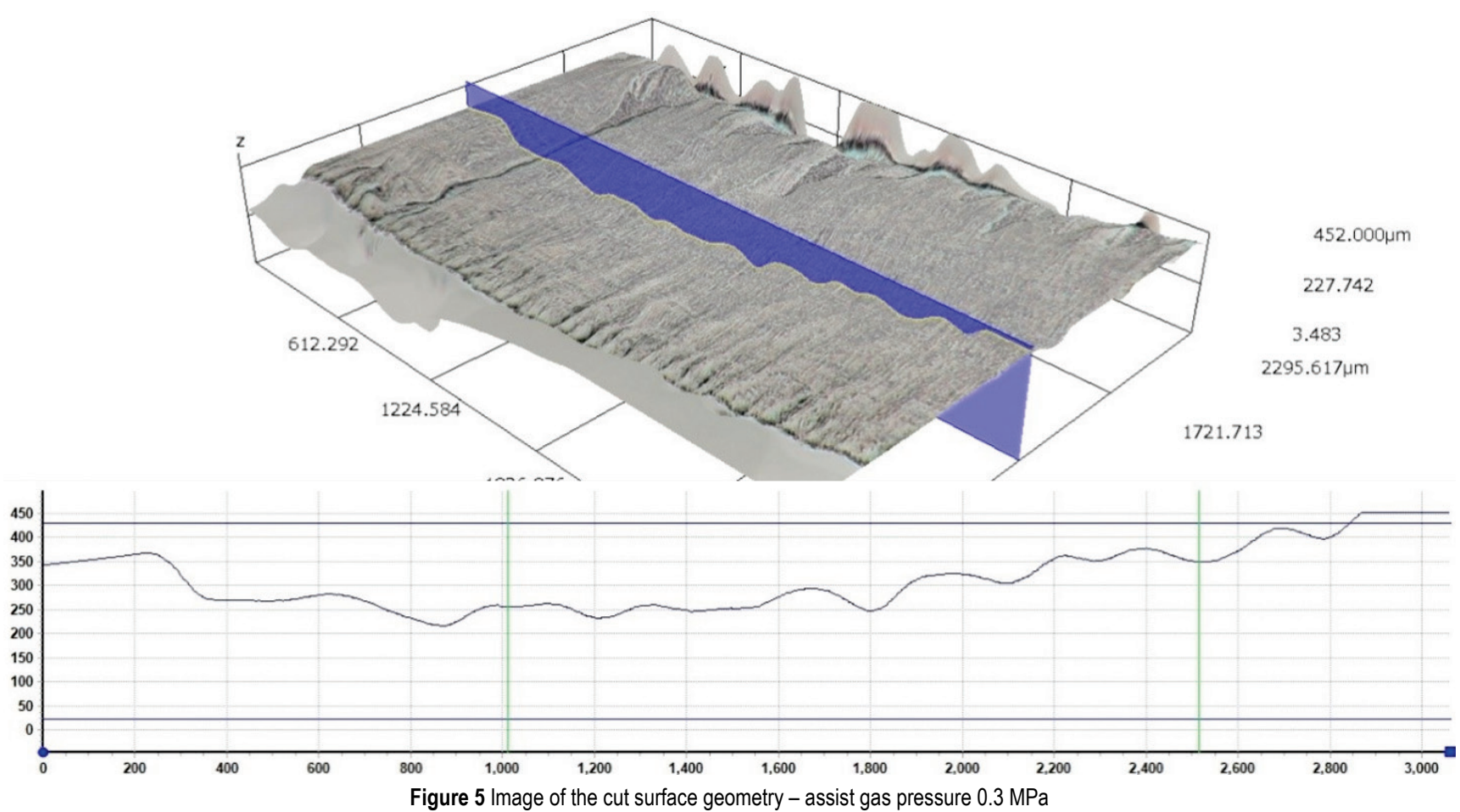


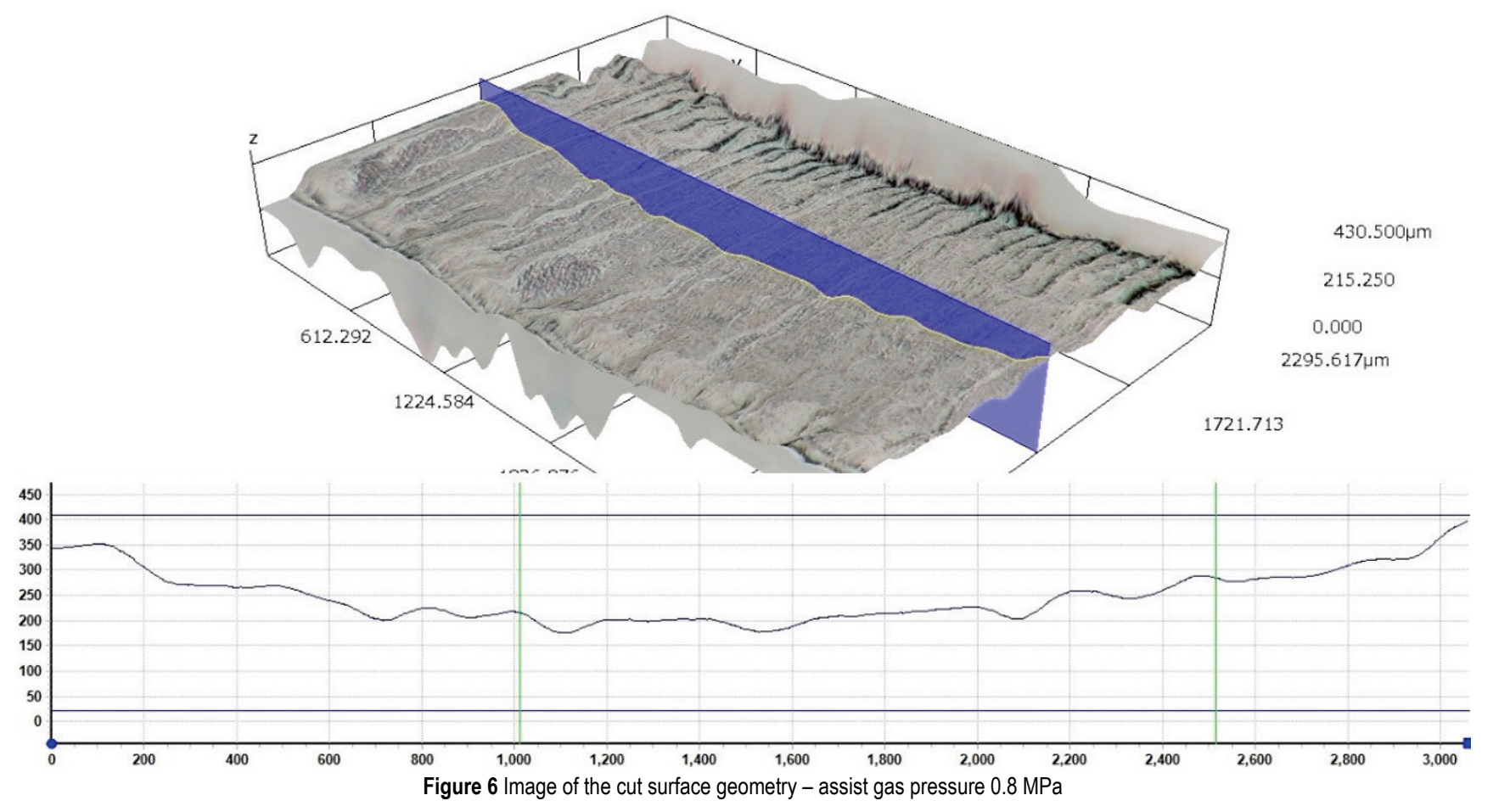

The assist gas pressure increase from 0.05 to $0.80 \mathrm{MPa}$ caused reduction of only about $6.7 \%$ of the $R a$ and $7.4 \%$ of the $R z$ roughness parameter. That could be considered as almost negligible improvement.

The effect of the ALP variation was more prominent. The change from $-3 \mathrm{~mm}$ to $+3 \mathrm{~mm}$ caused reduction of the $R a$ for $20 \%$ and of the $R z 25 \%$.

The strongest influence was imposed by the increase of the cutting speed from 1 to $6 \mathrm{~m} / \mathrm{min}$ that caused reduction of $R a$ for as much as $47.5 \%$ and reduction of $R z$ for $51 \%$.

During the ALP variation, a substantial corrugation of the material was noticed for the distance of $3 \mathrm{~mm}$ above the surface of the material, Fig. 1. That implied that the material burning process was not sufficiently stable - it can be even considered as unstable. The corrugation was caused by the diffused laser beam, what led to the conclusion that for obtaining the better surface quality the laser beam focus should be set under the material surface ( $3 \mathrm{~mm}$ below it). In that case, the surface was slightly rougher, but the burning process was more stable and material corrugation was less prominent.

Within the research reported in this article, those three cutting parameters were varied within the relatively narrow ranges, and more importantly, for the first two parameters for only three values per each parameter. Thus, the conclusions drawn from those experiments should be taken as an orientation, though they agree with the theoretical predictions and some results of other researchers. They point to the direction of the future research to performing the parameters variation within the wider ranges and with more steps during those variations.

\section{Acknowledgements}

Research presented in this paper was partially financially supported through realization of the projects KEGA no. 054 ŽU - 4/2012 and VEGA no. 1/0186/09
(Responsible investigator: Prof. Ing. Jozef Meško, PhD); by the European regional development fund and the Slovak state budget by the project "Research Center of the University of Žilina" and by the Ministry of Education, Science and Technological Development of Republic of Serbia through Grants TR35024 and ON174004.

\section{REFERENCES}

[1] Meško, J., Nigrovič, R., \& Zrak, A. (2017). The Influence of Different Assist Gases on Ductile Cast Iron Cutting by $\mathrm{CO}_{2}$ Laser. Archives of Foundry Engineering, 17(4), 109-114. https://doi.org/10.1515/afe-2017-0139

[2] Caristan, L. C. (2004). Laser cutting guide for manufacturing. Society of Manufacturing Engineers, Dearborn, Michigan, USA.

[3] Svelto, O. (2010). Principles of laser, Springer, Berlin. https://doi.org/10.1007/978-1-4419-1302-9

[4] Silvfast, W. T. (2004). Laser Fundamentals, Cambridge University Press, Cambridge. https://doi.org/10.1017/CB09780511616426

[5] Konar, R. \& Mičian, M. (2014). Non-destructive testing of welds in gas pipelines repair with phased array ultrasonic technique. Manufacturing Technology, 14(1), 42-47.

[6] Konar, R., Patek, M., \& Mičian, M. (2014). Experimental measurements and numerical simulation of bridge construction welding at low temperatures. Communications, 16(3A), 130-135.

[7] Sejč, P. \& Kubiček, R. (2015). Analysis of arc stability MIG brazing of $304 \mathrm{~L}$ stainless steel using solid and flux-cored wire. Manufacturing Technology, 15(1), 86-92.

[8] Radek, N., Meško, J., \& Zrak, A. (2014). Technology of laser forming. Manufacturing Technology, 14(3), 428-431.

[9] TRUMPF Werkzeugmaschinen GmbH + Co. KG. 2007. Technical information - Laser processing $-\mathrm{CO}_{2}$ laser. $<$ http://www.trumpf-laser.com/index.php?eID=tx_naw securedl\&u $=0 \&$ file $=$ fileadmin/DAM/trumpf-laser.com /Technische_Infos/TI_Laser_processing_CO2-Lasers.PDF $\& \mathrm{t}=1431301513 \& \mathrm{hash}=\mathrm{b} 8 \mathrm{~b} 5 \mathrm{~d} 228412 \mathrm{cb} 1 \mathrm{cb} 218285732 \mathrm{c} 9 \mathrm{~d}$ $7 \mathrm{~b} 3 \mathrm{f}>$ (Accessed on 07.02.2015).

[10] TRULASER. 2008. [online]. 2014, <http://www.sk.trumpf. com/index.php?eID $=$ tx_nawsecured $\& u=0 \&$ file $=$ fileadmin $/$ 
DAM/sk.trumpf.com/Prospekte/TruLaser-SK.PDF\&t= 1431272900\&hash=e169a4de6fcb624b457f38c24b19e246> (Accessed on 07.02.2015).

[11] Manobar, M. (2006). $\mathrm{CO}_{2}$ laser beam cutting of steels: Material issues. Journal of Laser Applications, 18(2), 101112. https://doi.org/10.2351/1.2193173

[12] Yilbas, B. S. \& Sahin, A. Z. (1995). Oxygen assisted laser cutting mechanism - a laminar boundary layer approach including the combustion process. Optics \& Laser Technology, 27(3), 174-184. https://doi.org/10.1016/0030-3992(95)93638-8

[13] Yilbas, B. S. (2004). Laser cutting quality assessment and thermal efficiency analysis. Journal of Materials Processing Technology, 155-156, 2106-2115. https://doi.org/10.1016/j.jmatprotec.2004.04.194

[14] Chen, K., Yao, Y. L., \& Modi, V. (1999). Numerical Simulation of Oxidation Effects in the Laser Cutting Process. International Journal of Advanced Manufacturing Technology, 15, 835-842. https://doi.org/10.1007/s001700050140

[15] Madić, M., Radovanović, M., Nedić, B., \& Marušić, V. (2015). Multi-objective optimization of cut quality characteristics in $\mathrm{CO}_{2}$ laser cutting of stainless steel. Tehnički vjesnik, 22(4), 885-892. https://doi.org/10.17559/TV-20140211234150

[16] Zeleňák, M., Valíček, J., Klich, J., \& Židková, P. (2012). Comparison of surface roughness quality created by abrasive water jet and $\mathrm{CO}_{2}$ laser beam cutting. Tehnički vjesnik, 19(3), 481-485.

[17] Dahil, L. \& Dahil, I. (2014). Comparison of heat effects associated with metal cutting method on ST37 alloy steel. Metalurgija, 53(1), 235-238.

[18] Lugan, A., Hilton, P. A., \& Taylor, D. W. (2002). The Effects of Steel Composition on the Laser Cut Edge Quality of Carbon and C-Mn Steels. Proceedings of ICALEO 2002, Scottsdale, Arizona. 1-8.

[19] Petru, J., Zlamal, T., Cep, R., Monkova, K., \& Monka, P. (2013). Influence of cutting parameters on heat-affected zone after laser cutting. Tehnički vjesnik, 20(2), 225-230.

[20] Whitehouse, D. (2012). Surfaces and their Measurement. Butterworth - Heinemann, Boston.

[21] http://www.steelspecs.com/EN10025-2/EN10025-2S235 JRSTEELPLTAE.html (Accessed on 02.08.2015).

\section{Contact information:}

Jozef MEŠKO, professor, Ing., PhD

Department of Technological Engineering,

Faculty of Mechanical Engineering, University of Žilina

Univerzitná 1, 01026 Žilina, Slovakia

E-mail: jozef.mesko@fstroj.uniza.sk

Andrej ZRAK, Ing., PhD

Department of Technological Engineering

Faculty of Mechanical Engineering, University of Žilina,

Univerzitná 1, 01026 Žilina, Slovakia

E-mail: andrej.zrak@fstroj.uniza.sk

Rastislav NIGROVIČ, Ing.

Department of Technological Engineering,

Faculty of Mechanical Engineering, University of Žilina,

Univerzitná 1, 01026 Žilina, Slovakia

E-mail: rastislav.nigrovič@fstroj.uniza.sk

Ružica R. NIKOLIĆ, professor, Ing., PhD, SM., MSc

Faculty of Engineering, University of Kragujevac

Sestre Janjic 6, 34000 Kragujevac, Serbia

and

Research Center, University of Žilina

Univerzitna 1, 01026 Žilina, Slovakia

E-mail: ruzicarnikolic@yahoo.com 